\title{
High strength metallurgical graphene as an additional reinforcing phase for carbon fibre composites
}

\author{
A. Kunikowska ${ }^{1}$-W. Szymanski ${ }^{1}$ A. Jedrzejczak ${ }^{1} \cdot$ S. Lipa ${ }^{1} \cdot$ M. Galazka ${ }^{2} \cdot$ M. Szlachetka ${ }^{3} \cdot$ P. Kula ${ }^{1}$
}

Received: 17 June 2019 / Accepted: 25 November 2019 / Published online: 24 February 2020

(c) The Author(s) 2020

\begin{abstract}
The main objective of the present study is an elaboration of a method for a transfer of high strength metallurgical graphene (HSMG) and its introduction into the structure of fibre laminates. In this work, two transfer procedures have been established: a transfer onto structural adhesive film (SAF) and a direct transfer onto two types of carbon fibre pre-impregnates (uniaxial and biaxial cloth). An important novelty of the presented experimental work is a use of scanning electron microscopy (SEM) operating in the absorbed electrons (AE) mode. This technique enables the evaluation of graphene continuity on a large area within a relatively short time. The SEM/AE technique made it possible to ascertain that the transferred graphene was characterised by a low level of defects, indicating that it could be used as a reinforcing phase in composites. Both transfer procedures, one onto SAF and the other directly onto the pre-impregnates were used for manufacturing flat laminates as well as tubular profiles. The flat samples, containing 0.68 ppm HSMG by weight, exhibited a $9 \%$ increase of low cycle fatigue strength. The tubular profiles (bicycle components) with approximately $0.22 \mathrm{ppm}$ of HSMG exhibited a significant increase of fatigue wear during initial tests. In addition, no fatigue delamination was observed at interfaces between the pre-impregnates separated with HSMG graphene.
\end{abstract}

Keywords Composites $\cdot$ Graphene $\cdot$ Mechanical properties $\cdot$ Resins $\cdot$ Fibers

\section{Introduction}

A number of reports in the literature describe an application of various forms of graphene flakes as a reinforcing phase in polymer matrix composites [1-15]. A number of reports in the literature describe the application of various forms of graphene flakes as a reinforcing phase for polymer matrix composites [1-15] inter alia polyethylene (PE) [1, 2, 8, 12], poly (vinyl alcohol) (PVA) [3, 10, 13], polymethylmethacrylate (PMMA) [4], poly(vinyl chloride) (PVC) [6], polypropylene [7], polyimide (PI) [9], polyamide (PA) $[5,11]$ or epoxy resins $[14,15]$. An addition of $6 \mathrm{wt} \%$ of graphene nanosheet (GNS) to a PE matrix resulted in an

$\triangle$ P. Kula

piotr.kula@p.lodz.pl

1 Institute of Materials Science and Engineering, Lodz University of Technology, 1/15 Stefanowskiego St., Lodz, Poland

2 Advanced Graphene Products Sp. z o.o., Antoniego Wysockiego 4 St., Kisielin, Zielona Gora, Poland

3 Engineo Sp. z o.o., Leszno 59 St., Przasnysz, Poland increase of its elastic modulus from 520 to $580 \mathrm{MPa}$ [1]. Also in the case of a composite based on ultra-high molecular weight polyethylene (UHMWPE), the addition of $1 \mathrm{wt} \%$ of graphene oxide (GO) stimulates an increase of its tensile modulus from 864 to $1236 \mathrm{MPa}$ [8]. As Li and Xie report $0.2 \mathrm{wt} \%$ of GO blended with high-density polyethylene (HDPE) composite results in an increase of stress at break from 18.1 to $24.2 \mathrm{MPa}$ and of strain at break from 850 to $1941 \%$ [12]. The effect of reinforcing the PI matrix by the addition of $2 \mathrm{wt} \%$ of functionalized graphene sheet (FGS) was also demonstrated, by an increase of tensile strength from 88.4 to $118.5 \mathrm{MPa}$ [9]. The addition of $4 \mathrm{wt} \%$ of chemically modified graphene (CMG) to the PMMA showed an increase of the modulus from 3.43 to $4.53 \mathrm{GPa}$ [4]. In turn, the addition of $0.6 \mathrm{wt} \%$ of functionalized graphene (FG) to a composite based on PA improved tensile strength by $35 \%$, and elongation at break by $200 \%$ [5]. PP based composite with the addition of 1.9 vol\% of FG showed an increase of modulus from 0.6 to $1.16 \mathrm{GPa}$ [7]. The addition of $0.1 \mathrm{wt} \%$ of reduced graphene oxide (rGO) to the PA composite causes a increase of strength by $210 \%$ and of modulus by $240 \%$ [11]. Composite manufactured as a blend of $2 \mathrm{wt} \%$ 
of graphene nanoflakes with PVC matrix improves tensile strength from 24 to $55 \mathrm{MPa}$, as well as increases modulus from 0.8 to $2 \mathrm{GPa}$ [6]. The addition of $0.8 \mathrm{wt} \%$ of partially reduced graphene oxide (prGO) to the PVA polymeric base improves tensile strength from 32 to $69 \mathrm{MPa}$ [3]. In turn, $3.5 \mathrm{wt} \%$ of GO added to the PVA resulted in an increase of its tensile strength from 22 to $29 \mathrm{MPa}$ [13]. Songs group manufactured a composite material as a graphene/PVA sandwich [10]. It is also possible to make a composite based on epoxy as a matrix with the addition of various graphene fillers [14]. For example, $0.2 \mathrm{wt} \%$ of thermally reduced graphene oxide used as filler in epoxy composite improves its elastic modulus from 2.9 to $3.1 \mathrm{GPa}$ [15].

In addition, both graphene flakes and large-surface graphene produced by chemical vapour deposition (CVD) have been applied as an auxiliary reinforcing phase for carbon fibre reinforced polymer (CFRP) composites [16]. The reports in the literature regarding composites of this type discuss only reinforcement of the matrix with graphene flakes, and the results are neither unambiguous nor consistent.

In Ref. [17], an increase of tensile strength of epoxy resin from 55 to $66 \mathrm{MPa}$ was obtained through the application of $0.25 \mathrm{wt} \%$ of graphene nanoplatelets (GNPs). In Ref. [18], the reinforcement of an epoxy resin polymer matrix with $0.54 \mathrm{vol} \%$ of graphene oxide (GO) resulted in an increase of its tensile strength from 72.6 to $79 \mathrm{MPa}$. Similarly, an increase from 77.52 to $82.31 \mathrm{MPa}$ was obtained in Ref. [19] by adding $1 \mathrm{wt} \%$ of GNPs to an epoxy resin polymer matrix that was additionally reinforced with a single layer of carbon fibre $(\mathrm{CF})$.

For multi-layer fibre composites, reinforcement effects were observed through significantly higher relative values of their mechanical properties. Mannov et al. [20] demonstrated a 53\% increase of critical stress (from $170 \mathrm{MPa}$ at $0 \mathrm{wt} \% \mathrm{GO}$ to $260 \mathrm{MPa}$ at $0.3 \mathrm{wt} \% \mathrm{GO}$ ) for a pre-impregnated composite consisting of an epoxy matrix filled with GO and additionally reinforced with glass fibre reinforced polymer (GFRP). For similar pre-impregnated composites reinforced with CFRP, a 19\% increase of compressive strength was obtained (from 150 to $170 \mathrm{MPa}$ with the addition of $0.3 \mathrm{wt} \% \mathrm{GO})$. Moreover, Shen et al. [17] created a 13-layer pre-impregnate using carbon fibre reinforced plastic (CFR plastic) to reinforce an epoxy matrix filled with GNPs. As a result, its strength was increased from $419 \mathrm{MPa}$ for $0 \mathrm{wt} \%$ GNPs to $446 \mathrm{MPa}$ for $0.25 \mathrm{wt} \%$ GNPs. In Ref. [21], a hybrid epoxy composite was fabricated, filled with different wt $\%$ of GO, and reinforced with CF. An increase by $66 \%$ of bending critical strength (420 MPa for $0 \mathrm{wt} \%$ GO to $700 \mathrm{MPa}$ for $0.3 \mathrm{wt} \% \mathrm{GO}), 72 \%$ in the bending modulus (20,000 MPa for $0 \mathrm{wt} \% \mathrm{GO}$ to $330,000 \mathrm{MPa}$ for $0.3 \mathrm{wt} \% \mathrm{GO}$ ), and by $25 \%$ of shear strength between layers (32 MPa for $0 \mathrm{wt} \% \mathrm{GO}$ to $41 \mathrm{MPa}$ for $0.3 \mathrm{wt} \% \mathrm{GO}$ ) was observed in that study.
In all the cases described above, graphene flakes constitute a random geometric filling of the polymer matrix. On the other hand, the directional impact of an ordered (laminar) reinforcement on the mechanical properties of composite materials is well known. A laminar arrangement of the reinforcement can be achieved by introducing CVD large-surface graphene to the composites; however, there are no reports on that subject in the literature. The transfer technology is a likely problem in this case. One possible solution is the application of high strength metallurgical graphene (HSMG), characterised by high strength and a potential for effective transfer [22-28]. This original 2D material is grown on the surface of liquid copper in the form of quasimonocrystalline monolayer [22, 23, 28]. It exhibits semi-conductive behaviour [27,28], in a consumption useful properties of various new sensors [24]. It also offers high strength and a affinity to gaseous hydrogen, which may be used in a manufacture nanocomposites for reversible storage of hydrogen $[25,26]$.

This study describes the direct transfer of large-surface graphene from metal process substrate onto pre-polymerised epoxy resin and two different types of pre-impregnates (unidirectional and bidirectional). An attempt to create a CFRP composite reinforced with HSMG using the two intermediate products is also described.

\section{Materials and methods}

\subsection{Materials}

In this study, the following materials were used: HSMG grown on a $\mathrm{Cu} / \mathrm{Ni}$ bimetallic substrate (according to patent no. EP2865646 A1), structural adhesive film (SAF) of $3 \mathrm{M}^{\mathrm{TM}}$ Scotch-Weld ${ }^{\mathrm{TM}}$ AF 163-2 $60 \mu \mathrm{m}$ (USA), unidirectional pre-impregnate [unidirectional carbon fabric with a resin content of $33 \%$ and grammage of $125 \mathrm{~g} / \mathrm{m}^{2}$ (SGL Group)], bidirectional pre-impregnate [bidirectional carbon fabric, plain, grammage of $200 \mathrm{~g} / \mathrm{m}^{2}$ with a resin content of $42 \%$ and thickness of $0.2 \mathrm{~mm}$ (Hexcel-HexPly)], anhydrous $\mathrm{FeCl}_{3}$ (Sigma-Aldrich), 40\% HF solution (Chempur), and $\mathrm{H}_{2} \mathrm{O}$.

\subsection{Identification of graphene morphology and structure on the forming matrix}

Preliminary inspection of the graphene continuity consisted of submerging the substrate in pure water for 3-5 min to reveal major discontinuities in the HSMG. A more detailed inspection was conducted within small areas by applying droplets of a strongly oxidising $0.1 \mathrm{M}$ aqueous solution of $\mathrm{FeCl}_{3}$ or through oxidation with a $30 \%$ solution of $\mathrm{H}_{2} \mathrm{O}_{2}$. This allowed one to obtain an information on the nature of 
defects in the form of growth shortages and cracks in the graphene layer, as well as on the graphene growth mechanism. An evaluation with the droplet oxidation method was performed at several points on the growth substrate. A drop of $\mathrm{FeCl}_{3}$ remained in contact with the substrate for approximately $5 \mathrm{~s}$, while a drop of $\mathrm{H}_{2} \mathrm{O}_{2}$ was in contact for $20 \mathrm{~s}$. Following oxidation time, the sheet of metal was rinsed thoroughly with deionised water. Changes in the growth surface of graphene before and after the droplet test were recorded using a Nikon Eclipse MA 200 optical microscope. Morphology of graphene layers was characterised using a Hitachi scanning electron microscope, model S-3000M, working in secondary electrons (SE) mode at an accelerating voltage of $5 \mathrm{kV}$.

The bond structure of the HSMG was examined with the help of Raman spectroscopy. An inVia Renishaw Raman spectrometer working at a wavelength of $785 \mathrm{~nm}$ was used for that purpose, with the measurements being carried out at several sites of samples. The laser power on the surface of the samples was $20 \mathrm{~mW}$, and the laser spot size was $800 \mathrm{~nm}$. All the measurements were performed under ambient conditions.

\subsection{Technological concepts}

Two technological concepts were tested: a transfer of graphene onto SAF as an intermediate phase during the creation of the composite, and a direct transfer onto pre-impregnates (prepregs) with unidirectional and bidirectional arrangements of CF. A schematic representation of graphene transfer on SAF/prepreg is shown in Fig. 1. Structural adhesive film (SAF)/prepreg was applied on a bimetallic growth substrate covered with HSMG.

Using a roller made of high-density foam, the SAF/ prepreg was pressed on the substrate surface, and the system was then passed through a set of 4 pairs of rollers. Subsequently, it was subjected to a pressure of $400 \mathrm{~N}$ for $60 \mathrm{~min}$. Pressing was performed using a smooth intermediate surface. After manual stocking and preliminary lamination, a green compact was placed into a vacuum bag made of a diaphragm membrane and sealed using sealing tape. The process was carried out under an atmosphere of -0.7 bar over $60 \mathrm{~min}$ to achieve better binding of the substrate with graphene to the SAF/prepreg. The operating system enabled air to be removed from the laminate during simultaneous pressing of individual layers.

\subsection{Separation of intermediate product from the graphene forming matrix}

Separation of the HSMG-(SAF/prepreg) from the forming matrix was achieved with the help of chemical etching. The metallurgical substrate was etched out within $24 \mathrm{~h}$ by an application of $1 \mathrm{M}$ aqueous solution of $\mathrm{FeCl}_{3}$ at room temperature.

\subsection{Identification of metallurgical graphene morphology and structure on the SAF/prepreg}

Initially, an evaluation of the HSMG transfer was performed by testing electrical resistance of graphene on the SAF substrate at multiple points within a square using a UNI-T70b multimeter. In the case of carbon prepregs, such a simple evaluation with a multimeter is not possible because the prepreg conducts electricity (a small content of epoxy resin causes exposure of the carbon fibres). A Hitachi S3000N scanning electron microscope working in $\mathrm{AE}$ mode at an accelerating voltage of $5 \mathrm{kV}$ was used for precise evaluation of the efficiency of the transfer of graphene onto the SAF and prepregs. In the AE mode, only the current of the incoming beam and the table current are compared, therefore, enabling a comparison between materials with substantially different electrical conductivities.

\subsection{Fatigue tests}

\subsubsection{Flat sample tests by three-point bending}

Fatigue strength analysis of composite samples, both graphene containing (PPG) and graphene free (PP), were carried out by the three-point bending test. For that purpose, a two-column strength tester LVF-50kN servo-hydraulic for static and dynamic tests by Walter + Bai was used. The load range for static and dynamic tests is taken $F=-50 \mathrm{kN}$. However, the working accuracy according to PN-EN ISO $7500-1$ corresponded to the $0.5 \%$ class.

\subsubsection{Fatigue tests of tubular profiles}

The testing station is presented in Fig. 2. It consists of a rigid support, holder, loading grip, and blade joint through which the force from the main actuator of the machine is transferred to the sample. The system assures that the direction of the force is always perpendicular to the sample axis, enabling free deformation of the sample in the deformation plane. The tests were carried out through one side bending. First, the sample was subjected to an initial force to apply a preloading, $\sigma_{\mathrm{m}}$. Next, cyclic tension, $\sigma_{\mathrm{a}}$, was applied using a constant deformation amplitude. The number of cycles required for a destruction of the composite or for the maximum force in the test to reach the value of the initial force, $\sigma_{\mathrm{m}}$, was recorded. An identification of the character and the formation mechanism of wear cracks was performed on cross-sections of the profiles using SEM analysis. 


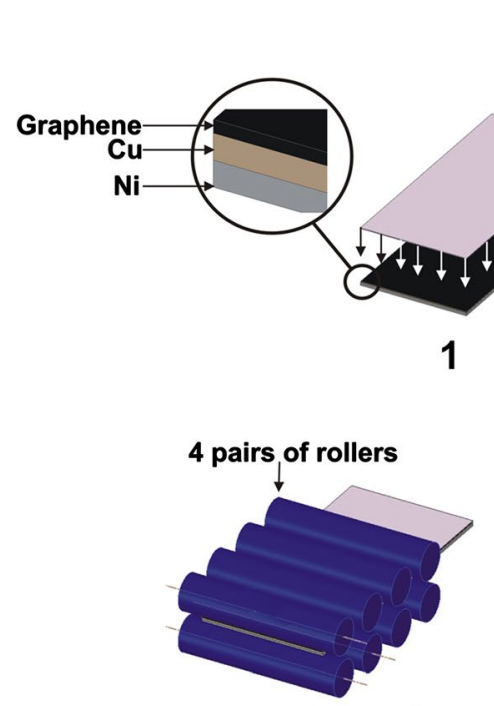

4

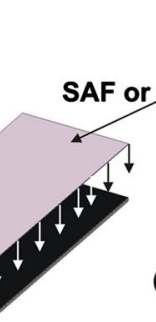

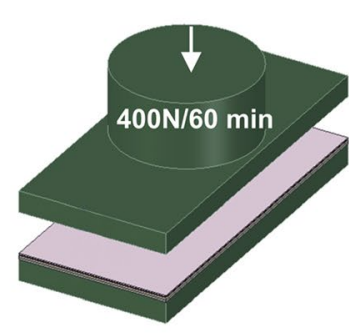

5

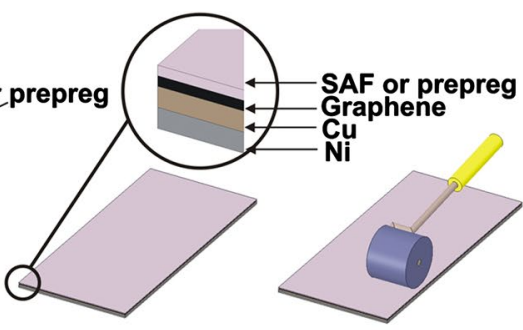

3
$-0.7 \mathrm{bar} / 60 \mathrm{~min}_{4,4}$

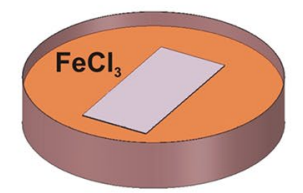

7
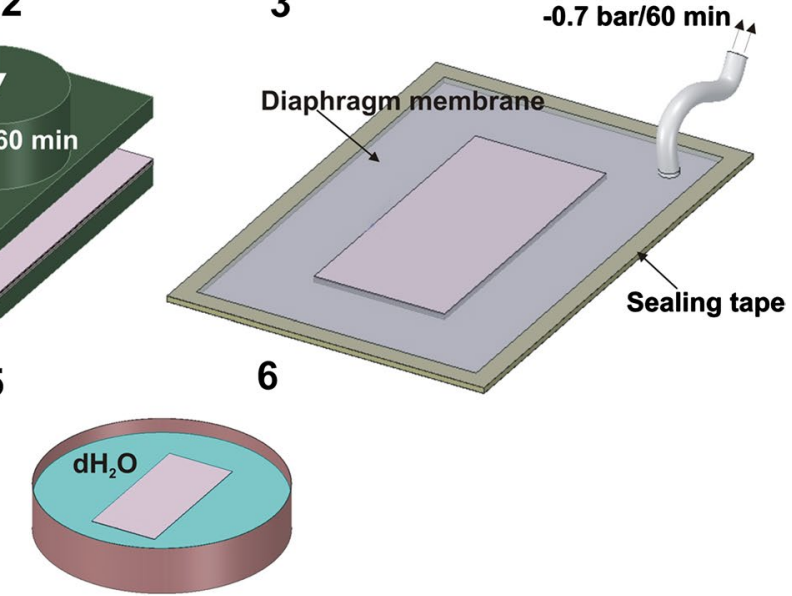

8

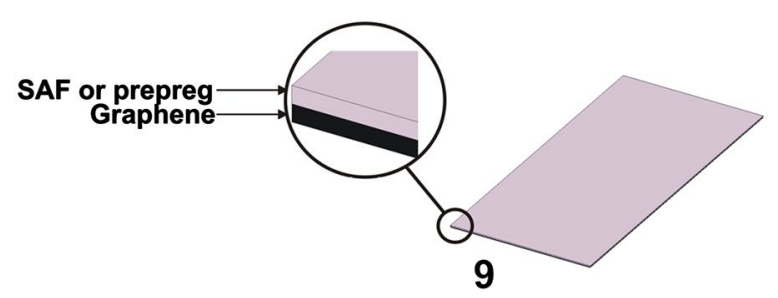

Fig. 1 Schematic representation of graphene transfer; (1) bimetallic growth substrate covered with HSMG (each layers are presented in the enlarged fragment); (2) HSMG covered bimetallic growth substrate coated with SAF or prepreg (each layers are presented in the enlarged fragment); (3) manual roller pressing of SAF or prepreg; (4) machine roller pressing of SAF or prepreg; (5) pressing of the stack

\section{Results}

\subsection{Qualitative evaluation of HSMG continuity on the forming matrix}

In the course of preliminary evaluation of the graphene continuity on the forming matrix, various macroscopic (Fig. 3a) and microscopic (Fig. 3b,c) defects were identified. After the water test, only those areas of the substrate that were characterised by a lack of significant macroscopic defects (discontinuities) when in contact with water (Fig. 3a-B) were selected. The droplet test revealed two HSMG growth mechanisms on the forming matrix: one dendritic (Fig. 3b) and one cellular (Fig. 3c). In our previous studies, cellular graphene was characterised

under force of $400 \mathrm{~N}$ for $60 \mathrm{~min}$.; (6) trapped air evacuation using vacuum bag; (7) Separation of the HSMG-(SAF/prepreg) from the forming matrix by $\mathrm{FeCl}_{3}$ etching of metallic components; (8) washing graphene-(SAF/prepreg) with $\mathrm{dH}_{2} \mathrm{O}$; (9) set of graphene-(SAF/ prepreg) ready for application in a composite structure (layers of graphene and $\mathrm{SAF} /$ prepreg are presented in the enlarged fragment) using SEM in SE mode [22, 23], while dendritic graphene was characterised in [28]. However, HSMG with structural discontinuities or formed by the dendritic mechanism were excluded from further investigations. This means that for the type of graphene characterised by a quasi-monocrystalline structure resulting from cellular growth on a liquid matrix was utilised subsequent tests. The HSMG formed by this mechanism exhibited a continuous structure in microscopic areas without extensive macroscopic defects, and it contained only a small amount of point defects or growth shortages (Fig. 3c-A). To confirm these observations the Raman spectrum of HSMG created by cellular growth was analysed. The main Raman band of the first order, also known as the $\mathrm{G}$ band $\left(\sim 1580 \mathrm{~cm}^{-1}\right)$ characteristic of all the $s p^{2}$ hybridised 


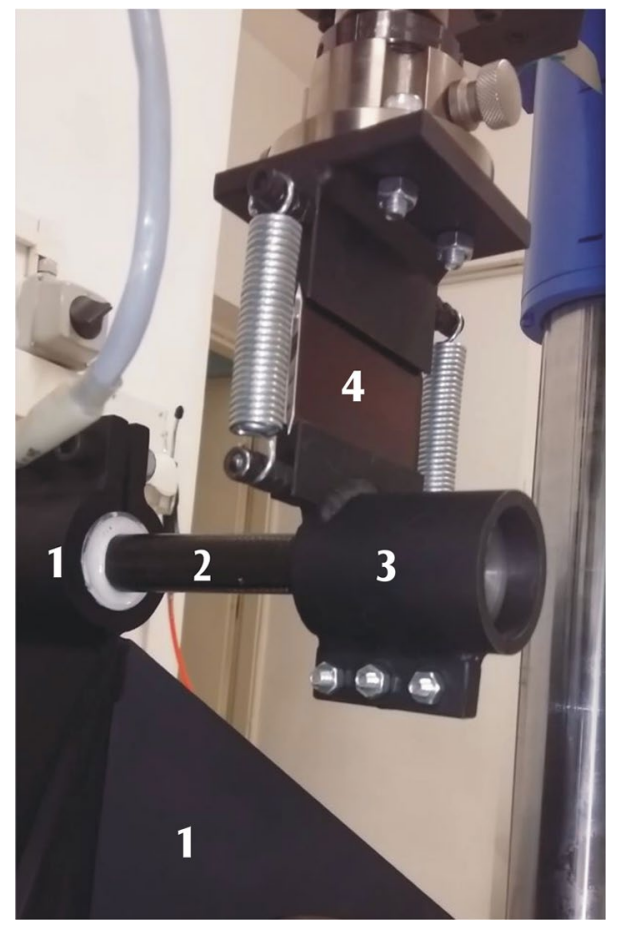

Fig. 2 Fatigue tests station with a sample mounted: (1) rigid support; (2) sample; (3) loading grip; (4) blade joint

carbon atoms, was observed (Fig. 4). The presence of the strongest $2 \mathrm{D}$ (or $\left.\mathrm{G}^{\prime}\right)$ band $\left(\sim 2700 \mathrm{~cm}^{-1}\right)$, which is a second-order Raman process originating from the in-plane breathing-like mode of carbon rings [29], and the D band (around $1320 \mathrm{~cm}^{-1}$ ) indicate the presence of point and linear defects.

\subsection{Evaluation of HSMG quality transferred onto SAF}

Compared to that of the base substrate an additional 2D band $\left(\sim 2700 \mathrm{~cm}^{-1}\right)$ was observed in the Raman spectrum of HSMG transferred onto SAF (Fig. 5). This confirms the presence of graphene on the SAF. Following the transfer process, a satisfactory continuity of coverage with graphene was achieved, as revealed by SEM/AE observations and electric resistance testing. After the transfer process onto the SAF, the HSMG was characterised by layer continuity with only a few microscopic defects (Fig. 6b-A). On a nonconductive adhesive film, every discontinuity (shortage) of graphene is visible as a dark area (Fig. 6). Additionally, after the transfer process, HSMG on the SAF substrate exhibited a satisfactorily low resistance of $2-9 \mathrm{k} \Omega$ /square see Table 1 .

\subsection{Evaluation of HSMG graphene continuity after transfer onto pre-impregnated carbon fibres}

HSMG was transferred onto unidirectional (Fig. 7a, b) and bidirectional (Fig. 7c, d) prepregs. In Fig. 7a, c SEM/AE images of the bare $\mathrm{CF}$ are presented. Conductive areas (i.e., the $\mathrm{CF}$ ) appear bright, while the non-conductive resin is
Fig. 3 Graphene grown on the $\mathrm{Ni} / \mathrm{Cu}$ substrate: a macroscopic observations-water test, b HSMG grown through the dendritic mechanism after etching in $30 \% \mathrm{H}_{2} \mathrm{O}_{2}$, c hexagonal (cellular) growth of HSMG after etching in $30 \% \mathrm{H}_{2} \mathrm{O}_{2}$ (A-graphene discontinuities, $\mathrm{B}$ - area free of any macroscopic defects, chosen for further transfer)
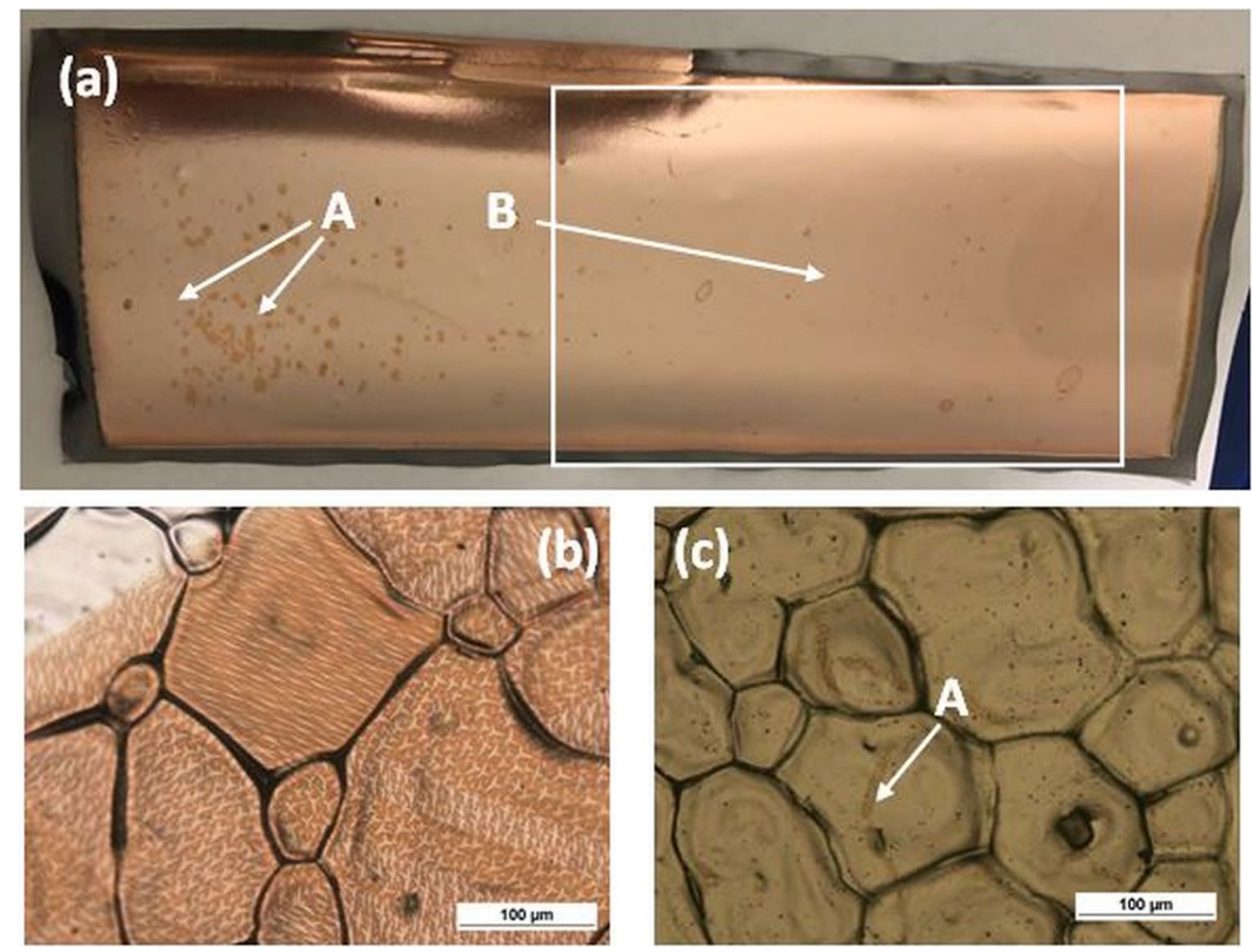


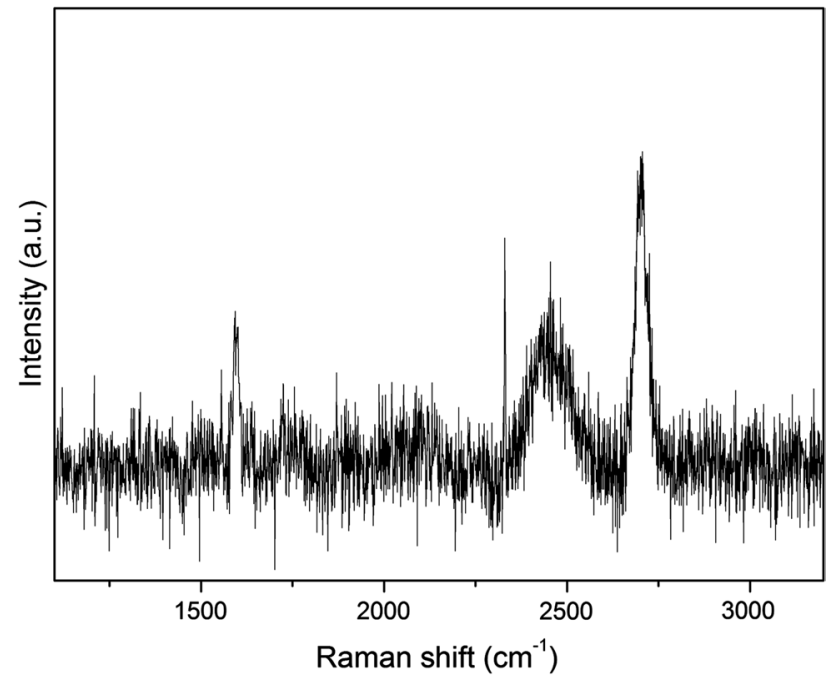

Fig. 4 Raman spectrum of HSMG grown through the cellular mechanism on the $\mathrm{Ni} / \mathrm{Cu}$ substrate

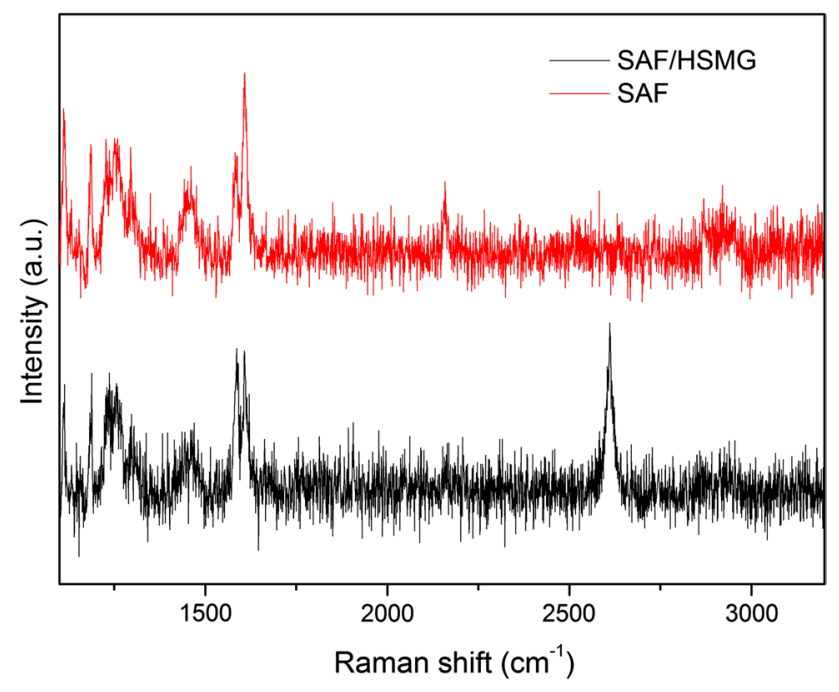

Fig. 5 Raman spectra of the SAF and HSMG on the SAF represented as dark areas. The SEM/AE images (Fig. 7b, d) show that the HSMG transferred onto both types of prepregs is of good quality, with only a few defects. Thus, SEM/AE is a good method for determination of the graphene transfer quality onto conductive as well as non-conductive substrates. In the images presented in Fig. 7d, only rare microscopic discontinuities of the graphene layer on the biaxial prepreg substrate are observed. More discontinuities can be seen on the unidirectional prepreg (Fig. 7b).

\subsection{Technological test}

The technological test consisted of manufacturing flat composite samples composed of 17 prepreg layers and a tubular profile composed of 4 prepreg layers. For manufacturing the flat composite samples, 17 prepregs with a biaxial fibre arrangement were used with three layers of SAF containing HSMG. Bench samples did contain SAF without HSMG. The composite was prepared in a quasi-isotropic $0^{\circ} 45^{\circ}$ $90^{\circ}-45^{\circ} 0^{\circ}$ system. SAF with and without graphene was applied between the 4th and 5th, 8th and 9th, and 13th and 14 th prepreg layers. A vacuum bag method was used to create the composite.

The low cycle fatigue test were performed for three different loads for each sample. Figure 8 shows the diagram of low cycle fatigue test results.

An analysis of the fatigue strength characteristics indicate that PPG samples show not only higher fatigue strength compared to PP samples, but also higher values of maximum stresses. For example: taking the values of maximum stress equal $630 \mathrm{MPa}$, the number of cycles to reach that value for PPG samples was approximately 5 times greater than for PP samples. Considering the same number of cycles' equal 5000 of the difference between stress values is about $9 \%$ in favor of PPG samples. The increase of the fatigue strength of PPG samples can be explained, among others by its failure mechanism observed by analysing fatigue fracture for both cases. Where graphene is used, there is a stronger interphase between prepregs. This phenomenon contributes to the reduction of the scatter of obtained results of the fatigue
Fig. 6 SEM/AE images of HSMG on SAF: a dark area at the bottom of the imageSAF without graphene, bright area-graphene on SAF; $\mathbf{b}$ point defects in the HSMG on $\mathrm{SAF}-\mathrm{A}$
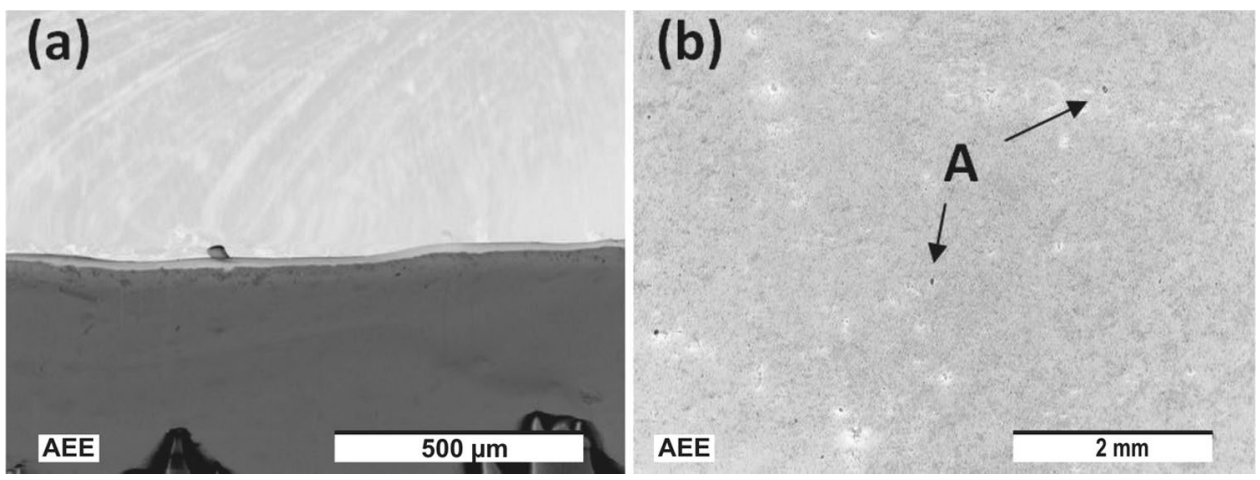
Table 1 Resistance of HSMG on SAF

\begin{tabular}{lccc}
\hline \multicolumn{4}{l}{ Graphene on SAF (k $\Omega /$ square $)$} \\
\hline 5 & 7 & 2 & 3 \\
7 & 3 & 4 & 9 \\
\hline
\end{tabular}

characteristics discussed. As seen in Fig. 8, the scatter of results for areas more loaded for the graphene reinforced composite (PPG) is much lower than for the regular composite (PP).

The technological test consisted of manufacturing a tubular profile. It was constructed of four prepregs: two unidirectional prepregs with graphene transferred directly onto them, as shown in Fig. 9b, and two bidirectional prepregs outside and inside of the tube. The above procedure produced the tubular profile presented in Fig. 9a. This profile was fixed in steel sockets using epoxy resin to create the sample (Fig. 9c) for testing of low-cycle fatigue with one-side bending.

In the preliminary fatigue tests, an evident positive impact of HSMG on the fatigue strength of the composite was observed. However, the fatigue data were widely divergent. Several samples reinforced with HSMG graphene successfully withstood one million cycles without any damage. Under the same testing conditions, the standard composite samples reached the initial $\sigma_{\mathrm{m}}$ after only 589 840 cycles. The damage to the samples never caused total fracture, but rather resulted in a local delamination of the polymer matrix. Microstructural examinations using SEM revealed two different fatigue mechanisms. Samples with HSMG were destroyed by delamination of the bidirectional prepreg, while samples without graphene failed through delamination within the unidirectional prepreg following a comparable number of cycles. For the overloaded samples, it was confirmed that delamination never occured at the sites of HSMG presence (Fig. 10A), but it rather took place at the border between non-reinforced layers (Fig. 10B) and inside the original structure of the bidirectional prepreg (Fig. 10C).

\section{Discussion}

Typically, graphene is transferred onto target substrates from the growth substrate on a supporting film made of polymer, commonly poly (methyl methacrylate) (PMMA) [23, 24, 28, 30-33]. However, this standard procedure was revealed to be inappropriate for creating composites
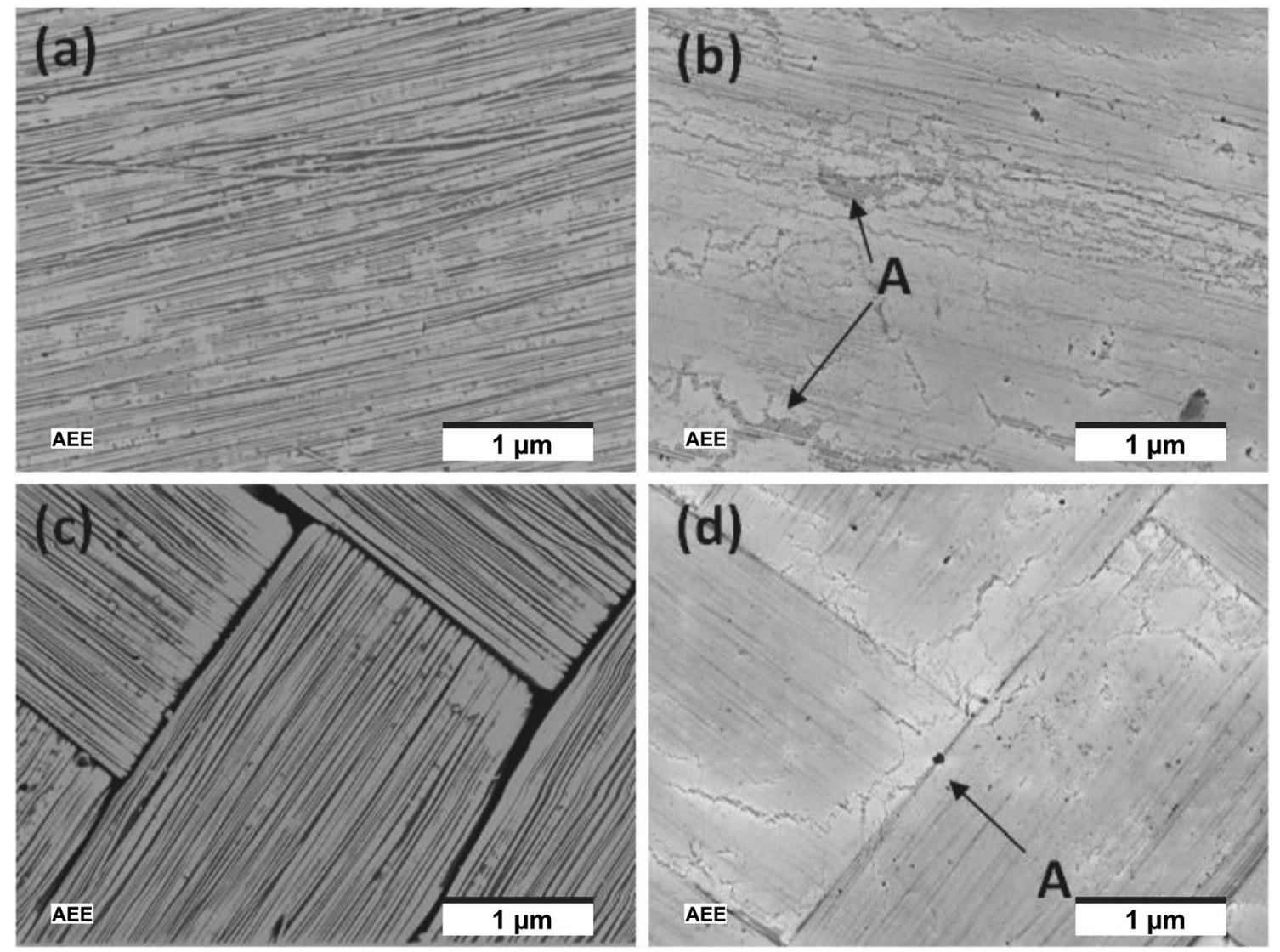

Fig. 7 SEM/AE images of prepregs before and after HSMG transfer: a unidirectional prepreg; b unidirectional prepreg with HSMG; $\mathbf{c}$ bidirectional prepreg; d bidirectional prepreg with HSMG; (A—defects in the HSMG after transfer onto the prepreg) 


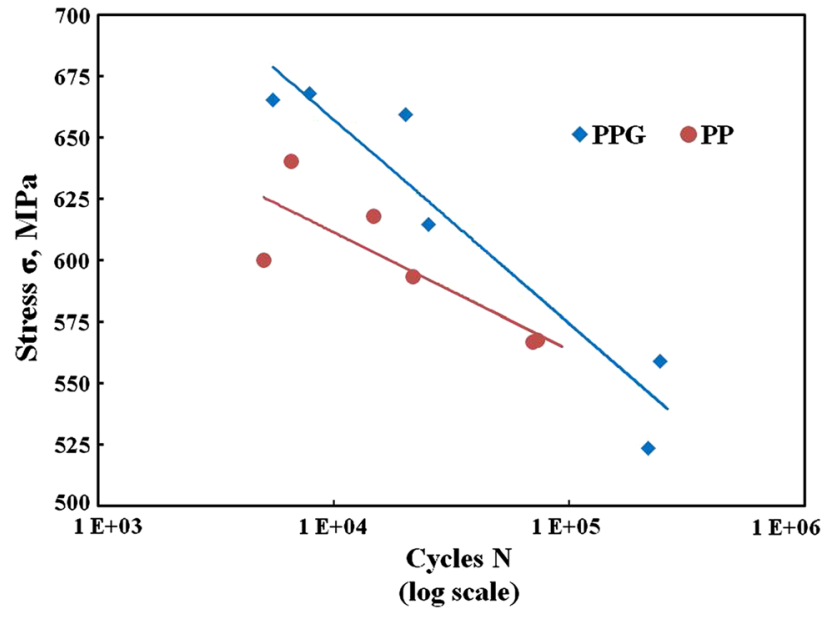

Fig. 8 Fatigue test results $\mathrm{S}-\mathrm{N}$ for three-point bending, a comparison of carbon fibre composites reinforced with HSMG graphene (PPG) introduced into the composite structure on SAF and carbon fibre composite (PP) with bare SAF sheet

(a)

(b)

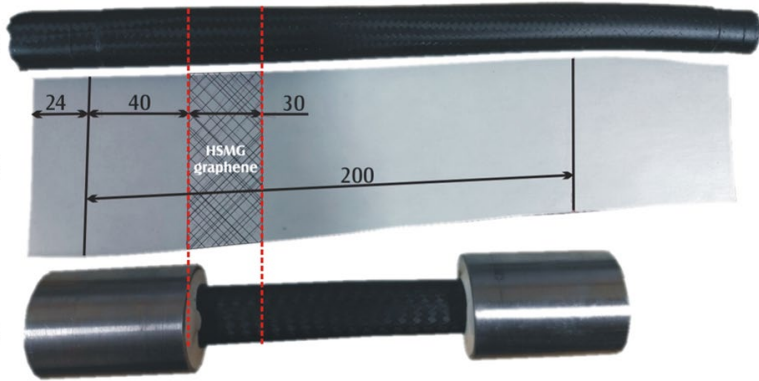

Fig. 9 A sample of carbon fibre composite for low-cycle one-side bending fatigue test: a real tubular profile used in bicycle frame construction; b prepreg pattern used for tubular profile formation with indicated site of graphene sheet introduction (hatched area); $\mathbf{c}$ final sample for the fatigue tests (red dashed lines show indicative reinforced section of tubular profiles)

from pre-impregnated carbon fibre. Employing a PMMA film with graphene in the composite production resulted in delamination. In this study, a procedure for transferring graphene onto adhesive film or directly onto a resinbased pre-impregnate was elaborated for the purpose of production of carbon fibre composites. The analysis of $\mathrm{SEM} / \mathrm{AE}$ images clearly demonstrate that it is possible to transfer graphene while maintaining a low level of mechanical defects resulting from the transfer. Satisfactory results were obtained both with an adhesive film having a relatively smooth surface of contact with graphene and with the prepregs. Biaxial and monoaxial pre-impregnates were characterised by a higher level of graphene defects compared to the adhesive film. The degree and nature of graphene defects on the unidirectional and bidirectional prepregs were similar.
An introduction of graphene into a composite with an epoxy matrix containing $\mathrm{CH}$ groups, aromatic rings, and hydroxyl groups should hing about interactions between these functional groups and its $\pi$-electrons [34] delocalized throughout the entire surface of the large-format graphene piece placed between the resin layers. Though these interactions are weak when occurring in great numbers they may improve the composite properties [35], including, indirectly, those related to mechanical strength or adhesion.

In the studies of flat samples, a significant improvement of mechanical properties was observed in the fatigue tests. The 9\% increase of low cycle fatigue strength has been achieved for PPG specimens which contained as little as 0.68 ppm graphene by weight. More impressive was an increase of the cycle number at failure that was obtained for PPG samples maintained at constant stress (up to 200\%).

The initial fatigue strength tests of bicycle tubular profiles confirmed the observed reinforcing effect. The PPG tubular sample reached 1,000,000 cycles whereas the PP tubular sample has been destroyed after 589,840 cycles using the same pulsing load. It should be emphasised that the amount of graphene introduced into the structure of the composite was only $0.22 \mathrm{ppm}$ in this case.

The presence of $\mathrm{CH}-\pi, \pi-\pi$, or $\mathrm{OH}-\pi$ interactions may lead to an improvement of the adhesion between individual prepregs within the composite, which is strongly suggested by the lack of delamination observed at the HSMG surfaces (SEM observations). Additionally, the reinforced polymer matrix makes it difficult for the fibres to move within the composite at the compressed part of the profile, therefore, preventing fibre micro-buckling, which is one of the main causes of destruction of fibre-reinforced polymers [36]. Reinforcement of composites with large-format graphene has one advantage compared to the more commonly used solutions employing graphene flakes [37-39]. The presented method results in a uniform reinforcement on the entire surface between the prepregs, rather than acting locally in the vicinity of individual flakes. Uneven dispersion of graphene flakes within the matrix may lead to local reductions of strength at conglomerate locations, thus having a negative impact on the strength of the whole composite [39].

The presented solution requires further systematic studies on the impact of large-format HSMG on the properties of composites. Perhaps a hybrid solution, i.e. a combination of large format graphene and a polymer matrix reinforced with graphene flakes, would result in a superposition of the properties of both of these solutions and eliminate the disadvantages of each. 

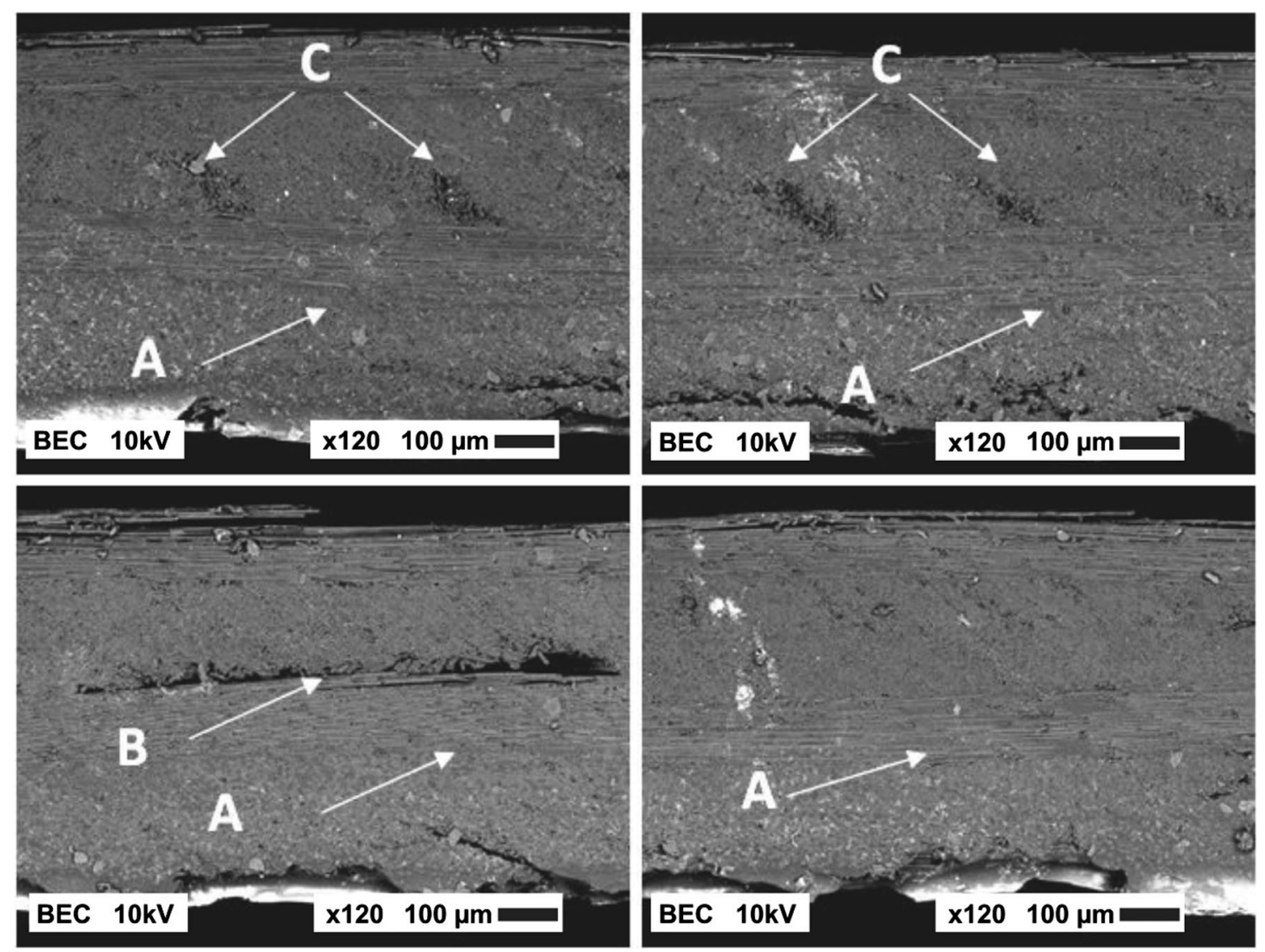

Fig. 10 Fatigue crack nucleation (SEM images): A-location of graphene introduction, B-delamination between prepregs without graphene, $\mathrm{C}-$ delamination of fibres from the epoxy matrix

\section{Conclusions}

1. Two effective methods for transferring large-format HSMG onto SAF and directly onto uni- and bidirectional prepregs were elaborated.

2. The effectiveness of SEM/AE observations for the assessment of the transfer quality of large areas of HSMG onto both conductive substrates (prepreg) and non-conductive substrates (SAF) was demonstrated.

3. Preliminary results confirmed a significantly positive effect of the introduction of HSMG on the fatigue strength of CFRP composites.

4. In the fatigue tests, no delamination between prepregs was observed in those sites where the HSMG had been introduced.

5. The increase at fatigue durability of HSMG-reinforced composites offers an added value to the performance of extremely strong CFRP composites.

6. A significant growth (9\%) of low cycle fatigue strength was recorded as a result of an introduction of $0.68 \mathrm{ppm}$ by weight of HSMG graphene into the CFRP.
7. The similar reinforcing effect was observed at the initial fatigue tests of industrial tubular CFRP profiles containing 0.22 ppm by weight of HSMG graphene.

Acknowledgements This work was supported by the Regional Operational Programme of the Mazowieckie Voivodeship for the years 2014-2020, project title "Development of an ultra-durable composite bicycle frame with the application of graphene, together with the development of technology for manufacturing thereof', Agreement Number: RPMA.01.02.00-14-5670/16-00.

Open Access This article is licensed under a Creative Commons Attribution 4.0 International License, which permits use, sharing, adaptation, distribution and reproduction in any medium or format, as long as you give appropriate credit to the original author(s) and the source, provide a link to the Creative Commons licence, and indicate if changes were made. The images or other third party material in this article are included in the article's Creative Commons licence, unless indicated otherwise in a credit line to the material. If material is not included in the article's Creative Commons licence and your intended use is not permitted by statutory regulation or exceeds the permitted use, you will need to obtain permission directly from the copyright holder. To view a copy of this licence, visit http://creativecommons.org/licenses/by/4.0/. 


\section{References}

1. Fim FC, Basso NRS, Graebin AP, Azambuja DS, Galland GB. Thermal, electrical, and mechanical properties of polyethylenegraphene nanocomposites obtained by in situ polymerization. $\mathrm{J}$ Appl Polym Sci. 2013;128:2630-7.

2. Das TK, Prusty S. Graphene-based polymer composites and their applications. Polym Plast Technol. 2013;52:319-31.

3. Yuan X. Enhanced interfacial interaction for effective reinforcement of poly(vinyl alcohol) nanocomposites at low loading of graphene. Polym Bull. 2011;67:1785-97.

4. Potts JR, Lee SH, Alam TM, An J, et al. Thermomechanical properties of chemically modified graphene/poly(methyl methacrylate) composites made by in situ polymerization. Carbon. 2011;49:2605-23.

5. Rafiq R, Cai D, Jin J, Song M. Increasing the toughness of nylon 12 by the incorporation of functionalized graphene. Carbon. 2010;48:4309-14.

6. Vadukumpully S, Paul J, Mahanta N, Valiyaveettil S. Flexible conductive graphene/poly(vinyl chloride) composite thin films with high mechanical strength and thermal stability. Carbon. 2011;49:198-205.

7. Quiles-Díaz S, Enrique-Jimenez P, Papageorgiou DG, Ania F, Flores A, Kinloch IA, Gómez-Fatou MA, Young RJ, Salavagione HJ. Influence of the chemical functionalization of graphene on the properties of polypropylene-based nanocomposites. Compos Part A. 2017;100:31-9.

8. Bhattacharyya A, Chen S, Zhu M. Graphene reinforced ultra high molecular weight polyethylene with improved tensile strength and creep resistance properties. Express Polym Lett. 2014;8(2):74-84.

9. Chen D, Zhu H, Liu T. In situ thermal preparation of polyimide nanocomposite films containing functionalized graphene sheets. ACS Appl Mater Interfaces. 2010;2(12):3702-8.

10. Song WL, Cao MS, Lu M-M, Bi S, et al. Flexible graphene/polymer composite films in sandwich structures for effective electromagnetic interference shielding. Carbon. 2014;66:67-76.

11. Fu X, Yao C, Yang G. Recent advances in graphene/polyamide 6 composites: a review. RSC Adv. 2015;5:61688-702.

12. Li H, Xie X-M. Polyolefin-functionalized graphene oxide and its GO/HDPE nanocomposite with excellent mechanical properties. Chin Chem Lett. 2018;29(1):161-5.

13. Yang X, Li L, Shang S, Tao X-M. Synthesis and characterization of layer-aligned poly(vinyl alcohol)/graphene nanocomposites. Polymer. 2010;51:3431-5.

14. Atif R, Shyha I, Inam F. Mechanical, thermal, and electrical properties of graphene-epoxy nanocomposites-a review. Polymers. 2016;8(281):1-37.

15. Tang L-C, Wan Y-J, Yan D, Pei Y-B, Zhao L, et al. The effect of graphene dispersion on the mechanical properties of graphene/ epoxy composites. Carbon. 2013;60:16-27.

16. Sporting goods with graphene material. Patent US 2013/0090193 A1, 11 Apr 2013.

17. Shen M-Y, Chang T-Y, Hsieh T-H, Li Y-L, Chiang C-L, Yang H, Yip M-C. Mechanical properties and tensile fatigue of graphene nanoplatelets reinforced polymer nanocomposites. J Nanomater. 2013. https://doi.org/10.1155/2013/565401.

18. Qiu J, Wang S. Enhancing polymer performance through graphene sheets. J Appl Polym Sci. 2011;119(6):3670-4.

19. Cakir F, Uysal H, Acar V. Experimental modal analysis of masonry arches strengthened with graphene nanoplatelets reinforced prepreg composites. Measurement. 2016;90:233-41.

20. Mannov E, Schmutzler H, Chandrasekaran S, Viets C, Buschhorn S, Tölle F, Mülhaupt R, Schulte K. Improvement of compressive strength after impact in fibre reinforced polymer composites by matrix modification with thermally reduced graphene oxide. Compos Sci Technol. 2013;87:36-41.

21. Pathak AK, Borah M, Gupta A, Yokozeki T, Dhakate SR. Improved mechanical properties of carbon fiber/graphene oxide epoxy hybrid composites. Compos Sci Technol. 2016;135:28-38.

22. Kula P, Pietrasik R, Dybowski K, Atraszkiewicz R, et al. Single and multilayer growth of graphene from the liquid phase. Appl Mech Mater. 2014;510:8-12.

23. Kolodziejczyk L, Kula P, Szymanski W, Atraszkiewicz R, et al. Frictional behaviour of polycrystalline graphene grown on liquid metallic matrix. Tribol Int. 2016;93B:628-39.

24. Pawlak R, Lebioda M, Rymaszewski J, Szymanski W, Kolodziejczyk L, Kula P. A fully transparent flexible sensor for cryogenic temperatures based on high strength metallurgical graphene. Sensors. 2017;17(51):1-14.

25. Kula P, Szymanski W, Kolodziejczyk L, Atraszkiewicz R, et al. High strength metallurgical graphene for hydrogen storage nanocomposites. Vacuum. 2016;129:79-85.

26. Kula P, Kaczmarek L, Zawadzki P, Kolodziejczyk L, et al. Functionality of graphene as a result of its heterogenic growth on $\mathrm{SiC}$ nanoparticles on the basis of reversible hydrogen storage. Int $\mathrm{J}$ Hydrogen Energy. 2014;39(34):19662-71.

27. Kula P, Pietrasik R, Kazimierski D, Atraszkiewicz R, Dybowski $\mathrm{K}$, Szymański W, et al. Resistance-temperature characteristics of CVD and high strength metallurgical graphene. Int J Nanotechnol. 2017;14(1/2/3/4/5/6):191-203.

28. Kula P, Szymanski W, Kolodziejczyk L, Atraszkiewicz R, Dybowski K, Grabarczyk J, et al. High strength metallurgical graphene-mechanisms of growth and properties. Arch Metall Mater. 2015;60(4):2535-41.

29. Ferrari AC. Raman spectroscopy of graphene and graphite: disorder, electron-phonon coupling, doping and nonadiabatic effects. Solid State Commun. 2007;143(1-2):47-57.

30. Pirkle A, Chan J, Venugopal A, Hinojos D, Magnuson CW, McDonnell S, et al. The effect of chemical residues on the physical and electrical properties of chemical vapor deposited graphene transferred to $\mathrm{SiO}_{2}$. Appl Phys Lett. 2011;99(12):122108.

31. Sachs R, Lin Z, Odenthal P, Kawakami R, Shi J. Direct comparison of graphene devices before and after transfer to different substrates. Appl Phys Lett. 2014;104:033103. https://doi. org/10.1063/1.4862063.

32. Huang L-W, Chang C-K, Chien F-C, Chen K-H, Chen P, Chen $\mathrm{F}-\mathrm{R}$, et al. Characterization of the cleaning process on a transferred graphene. J Vac Sci Technol A. 2014;32:050601. https:// doi.org/10.1116/1.4886735.

33. Xu J, Wang Q, Tao Z, Qi Z, Zhai Y, Wu S, et al. Field emission of wet transferred suspended graphene fabricated on interdigitated electrodes. ACS Appl Mater Interfaces. 2016;8:3295-300.

34. Du J, Cheng H-M. The fabrication, properties, and uses of graphene/polymer composites. Macromol Chem Phys. 2012;213:1060-77.

35. Xiao X, Xie T, Chengb Y-T. Self-healable graphene polymer composites. J Mater Chem. 2010;20:3508-14.

36. Darby MI, Kanellopoulos VN. Theory of fibre buckling in carbonfibre reinforced plastics. J Phys D Appl Phys. 1987;20:298.

37. Young RJ, Liu M, Kinloch IA, Li S, Zhao X, Vallés C, Papageorgiou DG. The mechanics of reinforcement of polymers by graphene nanoplatelets. Compos Sci Technol. 2018;154:110-6.

38. Mittal G, Dhand V, Rhee KY, Park S-J, Lee WR. A review on carbon nanotubes and graphene as fillers in reinforced polymer nanocomposites. J Ind Eng Chem. 2015;21:11-25.

39. Ovidko IA. Enhanced mechanical properties of polymer-matrix nanocomposites reinforced by graphene inclusions: a review. Rev Adv Mater Sci. 2013;34:19-25. 
Publisher's Note Springer Nature remains neutral with regard to jurisdictional claims in published maps and institutional affiliations. 